\title{
A Rock Amidst Turbulent Waters: China's Resilient Centre and its Machiavellian Management of Protests and Petitions
}

\author{
Sam Osborne
}

\section{Abstract}

In contemporary discourse, many struggle to fathom the ability of the Chinese leadership to maintain both economic and social stability despite clear and growing discontent within the Chinese populace. This is not mere good luck, but, rather, good management. Instead of crumbling in the face of widespread protest, as have many other authoritarian regimes, the Chinese leadership utilises Machiavellian methods of managing public discontent to legitimate or strengthen its own rule. In this sense, protest and the ways in which the leadership deals with it are, paradoxically, a driving force behind its overall stability. This essay examines four methods used by the Chinese leadership to respond to protests or petitions, including: the decentralisation of state power; the repression of certain protests and manipulation of facts; the tolerance of and concessions to certain protestors; as well as the cooptation of particularly vehement dissenters. It analyses the ways in which these methods interrelate and how they legitimise the Chinese leadership, ensuring continued stability and the maintenance of China's rise.

\section{Introduction}

Like the steadfast rock within the flowing stream that is so often contemplated by China's bygone poets, the leadership of the contemporary Chinese Partystate - the Centre - manages to remain resolute and resilient amidst turbulent tides of public discontent. Normally, such unrest might signal the impending demise of a regime, but China's authoritarian rule shows little sign of decline. This paradoxical 'coexistence of social disturbance and political stability' (Cai 2008a: 412) is explained by the Centre's numerous, rather Machiavellian, methods and political strategies of managing protests and petitions in China, 
which, rather than undermining its rule, actually strengthen and legitimises it. In this sense the term 'Machiavellian' is utilised to convey methods of statecraft characterised by cunning, deceit and expediency.

The decentralisation of state power and resultant multilevel power structure within China allows the Centre to manage protests in a manner that legitimises the overarching regime. Similarly, repression of certain protests (even violently undertaken) can be manipulated by the Centre to strengthen its own rule. State tolerance of and concessions to other protests and petitions also legitimates the regime in adhering to its propagated legalistic culture. Finally, cooptation by the Centre both of more meddlesome protestors themselves and policies espoused by such petitioners further strengthens its authority. This essay seeks to investigate these ways of managing discontent by the Centre, how they interrelate, and how it legitimises its authoritarian rule - in other words, how the rock manipulates the turbulent waters to cement its own place within the stream. While this essay focuses primarily on the rural population and their protests, it is important to note that urbanites have different perceptions of the Centre and employ different means (particularly involving the Internet) to voice their concerns, continuing the trend of a longstanding ideological and technological divide between rural and urban China.

\section{Decentralisation of State Power}

The decentralisation of the Party-state's power in post-Mao China has resulted in a political system with many levels of authority. This allows the Centre to tease out space in the resultant divided power structure to avoid blame and apportion responsibility for dealing with protests and petitions to lower level authorities (Cai 2008a: 411, 415). This structure allows the Centre to fuel its legitimacy and strengthen its rule through such protests by simply '[kicking] the ball back into the local government's court' (Wu 2009: 200). The Chinese state stands then as 'less a monolith than a hodgepodge of disparate actors' (O’Brien \& Li 2004: 93-94).

Because of the significant autonomy granted to local authorities under this power structure, there are wide gaps between what the Centre promises and what those local authorities deliver (Chen 2009: 22). This only serves to legitimise the rule of the Centre further, as protests often demand only the removal of unpopular lower level officials, or the local implementation of policies promised by the Centre, rarely questioning the leadership or the Party (Perry 2008: 45).

Due to its concern with protecting the regime's legitimacy and longevity, the Centre is likely to be (in fact and in the eyes of the people) more tolerant, whereas local officials, concerned as they are with task fulfilment and local issues, are 
more likely to be less indulgent (Cai 2008a: 417). The Centre's ability to direct responsibility for protests to such lower level officials under the divided power structure further strengthens the people's 'faith in the good intentions of Beijing' (O'Brien \& Li 2004: 86). This even leads to the belief of many protestors that, in fact, 'the Centre is on our side' (O'Brien \& Li 2005: 244-45).

The Centre's management of protests through the decentralisation of state power is perhaps best reflected in a maxim popular in the Chinese countryside:

$[\mathrm{T}]$ he Centre is our benefactor (enren), the province is our relative, the county is a good person, the township is an evil person, and the village is our enemy. (O'Brien \& Li 1995: 778)

Interestingly, in the literature, commentators such as O'Brien and Li (2005: 24041) argue that these and other consequences of the multi-layered state in China (such as the Centre being kept 'in the dark' and 'unable to detect breaches of its policies') are necessarily unwanted by and detrimental to the Centre and its rule.

It is arguable, however, that such commentators fail to adequately appreciate and recognise that the decentralisation of state power, while certainly being heavily flawed, allows the Centre to maintain its legitimacy amidst popular discontent, something thoroughly invaluable to the continued resilience of an authoritarian regime. While this view might be cynical, the alternative interpretation glosses over the Machiavellian nature of the Centre's management of protests in that the Centre may not desire to "break through the host of "protective umbrellas" (baohu san) that local leaders use to fend off oversight' (O'Brien \& Li 2005: 241). In fact, as long as those baohu san remain in place, the Centre can 'pretend' not to know of any wrongdoing and escape blame and responsibility, either for the causes of discontent or for the handling of protests by local authorities (Cai 2008a: 430).

Arguably, by placing responsibility for the handling of such discontent in the hands of autonomous, powerful and somewhat impatient authorities keen to dispel the need for Central intervention, the Centre also prevents a 'lack of discipline' of protestors and ensures that any popular resistance is 'short lived, often isolated and does not challenge the regime' (Cai 2008a: 430), all the while maintaining and even strengthening its own rule.

Clearly, then, by manipulating the overarching divided power structure resulting from the decentralisation of state power, the Centre can safeguard the resilience of its rule by championing the politico-cultural tradition in China that 'while the local officials are corrupt, the Emperor is always good' (Zou 2009: 132). 


\section{Repression}

It might seem paradoxical to consider that repressive conduct by the Party-state in response to certain protests (even violently undertaken) could be managed by the Centre to increase its legitimacy. Yongshun Cai $(2008 a: 413,418)$ argues that such repression undermines an authoritarian regime's legitimacy and incurs other costs, including risks of retaliatory resistance. While this might generally be so, arguably Cai fails to acknowledge the Chinese Party-state's sway within the media and its attempts to monopolise all forms of communication. Whereas in contemporary China, the Internet and popular forms of microblogging (weibo) threaten to unsettle such a government monopoly, the Centre still expends tremendous resources in an attempt to control channels of communication and other social media. Through this vast expenditure of both financial and human capital, the Centre can manipulate the way in which protests are framed, and the repression used against them, so as to inevitably favour the state, justify its actions, and strengthen the Centre's rule. In truth attempts to reframe such incidents are not always successful. The capacity certainly does exist, however, to refashion an overtly repressive response into one that portrays the Centre in a more positive manner.

Of course, if repression of protests occurs locally and is conducted by lower level authorities, the Centre can rely upon the divided power structure discussed above to divert blame and responsibility elsewhere (Cai 2008a: 429). If large-scale repression of protests occurs above those levels, the Centre may still be able to manipulate the petitioning to its own advantage. For instance, after the Tiananmen Square massacre of 1989, suppression of protests was justified by the government's high-profile propaganda campaign, which was framed to quell 'alleged "hooligans" and "thugs"'. The Centre reassured its people that 'the sword of the state remained powerful, swift, and sure' (Baum 1992: 492).

Needless to say, any use of violence by citizens in protests allegedly justifies repression by the state (Cai 2008a: 426). Likewise, if the protests threaten social or political stability, even the military can be mobilised (Cai 2008b: 104). This issue of threats to social and political stability invokes the ancient fear held by both governments and citizens alike in China of chaos (luan). By cleverly exploiting that fear and framing protests in terms of affronts to stability, the Centre can inevitably justify any repressive action and, again, strengthen its own rule.

The Centre capitalises on the fear, held by many villagers especially, that any change would 'unseat the only entity that appears to have the commitment, power, and economic resources to improve their daily circumstances' (Wright 2010: 8), and also the pertinent worry that a freer society might itself lead to chaos (McCormick 2009: 109). For instance, mass protests erupted at Pubugou, 
Hanyuan County, in 2004 over plans to forcibly evict tens of thousands of local farmers prior to planned flooding for the Pubugou Dam. Once the discontent was framed as an 'illegal act' and the omnipresent fear of 'chaos' was invoked, the protests failed, and any repression by the state would likely have been justified in the eyes of people not privy to the petitions (Mertha 2008: 81).

Furthermore, LHM Ling (1994: 393) provides a fascinating argument of how violent repression of dissent by the state can be warranted under the Confucian discourse of parental governance, and can thereby legitimise and strengthen the rule of the Centre. Under that discourse, 'state-society relations reflect Confucian parent-child relations', whereby there exists a natural moral authority on the part of the state as the benevolent but firm parent, versus citizens who are deemed filial dependents (Ling 1994: 393). As a result, the parent-state is granted a license to 'exile dissenters as ungrateful spoilt brats who deserve to be "rectified"', and should exercise that moral duty to 'restore order and harmony in the Confucian family-state' (Ling 1994: 393-94).

For example, after the Tiananmen Square massacre, Deng Xiaoping dismissed the protestors as 'dregs of society' whose real purpose was to 'subvert our country and subvert our Party' (Ling 1994: 401).

Further, within this framework, moral suasion as used by the dissenters not only implicitly accepts the 'hegemonic norms' that maintain the ruling regime and favour its authority, but are also easily countered by the moral outrage of the parent-state (Ling 1994: 402). For these reasons, then, it is clear that the Centre can manipulate a repressive response to protests in numerous ways, all of which (paradoxically) strengthen and legitimise its own rule.

\section{Tolerance and Concessions}

The Centre also uses tolerance and concessions as means of managing protests and petitioning. Interestingly, Cai (2008a: 413, 414) argues that concessions are detrimental to the legitimacy of an authoritarian regime, as is tolerance, which he contends will lead only to more resistance.

Aain, it is arguable that Cai fails to situate tolerance and concessions within the context of legitimacy derived from continued economic growth, as well as the Confucian context of modern Chinese political culture, in which such acts will only further add to the 'benevolent' and 'forgiving' image of the parent-state, strengthening its rule. Regardless, the Centre is more likely to be tolerant and to concede to demands of protestors when discontent is pursued through the legal channels that are provided for by the state. By fostering a culture of alleged legalism, which mandates strict obedience to the legal system and an 
overarching rule of law, the Centre thus manages to artfully manipulate such protests and petitions to its own advantage. If dissatisfaction is aired through legal avenues or employs legal norms imposed by the Centre, this only further legitimises their rule.

The Centre has provided various lawful channels through which dissenters can voice their grievances, in doing so ensuring a 'win-win' situation with regard to their legitimacy: 'policy-based resisters' (diaomin) utilise 'laws, policies and other official communications to defend their interests', thereby simultaneously attesting to the legitimacy of the Centre's rule. Conversely, 'recalcitrants' (dingzihu), or 'illegal' protestors, invoke the Centre's inherent right to discipline wrongdoers and can be dealt with under law, thereby, again, confirming the Party-state's rule (Li \& O'Brien 1996: 31, 35).

An example of a lawful method provided for by the Centre through which a protestor can voice dissatisfaction is the Administrative Litigation Law introduced in 1989. While under this law citizens can sue malfeasant local officials, the Party retains immunity from suit (O'Brien \& Li 2004: 80). Again, this means that the Centre manages to further exploit the divided power structure of the Party-state by lawfully allowing protestors to target lower level authorities while retaining higher level regime validity.

Further, the Centre has given its citizens 'more laws (and other directives) to point to when filing charges' (O'Brien \& Li 1995: 764), fuelling the people's belief in the Centre's alleged adherence to legalism and further increasing its legitimacy when such laws are then utilised and responded to, often with tolerance or concessions.

Another lawful channel of protest managed by the Centre, and one that is again likely to receive responses of forbearance or indulgence, is the xinfang (or 'people's letters and visits') system of collective petitioning. While this is an additional legal avenue for citizens to 'air their grievances', it is also a means by which the Centre can ensure a 'close connection with the masses' (Zou 2009: 124, 126). Agreeably, Keyuan Zou (2009: 132, 134) goes as far as to say that it is 'a means of controlling society and the people', and that, for the Centre, the "ideal model of the xinfang in its mind would be like "a bird in a cage"" — in other words, in line with the reasoning put forward above, a lawful means of protest, highly controlled by the Centre, which is inherently rule-legitimating. Moreover, by tolerating and even condoning such contention, this arguably also solves the principal-agent problems resulting from the decentralisation of power (which, as shown above, are simultaneously manipulated by the Centre to its own advantage) (O'Brien \& Li 2005: 241). 
Thus the Centre manages protests in this way by 'empowering ordinary people to serve as watchdogs' (O'Brien 2003: 60), strengthening its rule by giving its citizens a sense of self-worth while concomitantly 'getting local feedback without holding substantive elections' (Weller 2008: 122).

Moreover, those diaomin (or 'rightful resisters' as O'Brien and Li dub them) who rely upon laws and policies promulgated by the Centre to frame their contention situate themselves within the culture of legalism championed by the Party-state, thereby strengthening its rule further. Their resistance is generally 'mindful and circumscribed, local and parochial, rather than national and autonomous' (Li \& O'Brien 1996: 54), and thus the Centre is more likely to react with tolerance or concessions rather than violent repression (although this is dependent on the media's input), which only reinforces their 'benevolent' rule.

In addition, Chinese politico-cultural tradition subscribes to a general 'right to rebel' stemming from Mencian thought (Perry 2008: 39) and, as diaomin also endorse 'waving the red flag to oppose the red flag' (Perry 2002: xxiii), they inevitably legitimise the pre-existing authoritarian rule. Any rights such resisters call for are also 'granted, not recognized' by the Centre (Hintzen 1994: 12-13), and thus advocating the implementation of such rights in turn presupposes the legitimacy of the Centre.

Clearly, then, by responding with tolerance of or concessions to those protests or petitions that operate within the Party-state's sphere of legality, the Centre is able to manipulate such discontent so as to strengthen its own legitimacy and rule, fortifying the tradition of 'critique within the hegemony' ( $\mathrm{O}^{\prime}$ Brien \& Li 2006: 5).

\section{Cooptation}

Finally, the Centre can also respond to protests by either coopting more meddlesome petitioners themselves into Party-state political mores, or by adopting such dissenters' policies. While both coopting protestors themselves and 'implementing the dissenters' reforms (Ling 1994: 402) potentially jeopardises the Centre's legitimacy as signs of weakness, again, this argument fails to hold water when the Confucian context of parental governance in China is taken into account. Here, such actions only strengthen the 'benevolent' rule of the Centre.

In fact, as Elizabeth Perry (2008: 45-46) rightly argues, the Centre's willingness to respond in such ways shows flexibility and pragmatism, an essential feature of Chinese morality and state behaviour. This is invaluable in ensuring the longevity of their rule. Furthermore, incorporating more troublesome individuals into the existing power structure enables the Centre to find favour 
with those who could potentially upset its rule (including outsiders), as well as displaying forbearance and acceptance to its citizenry. An example is the Party's cooptation of the outspoken Yu Jianrong as a kind of teacher of ethics to state officials (Li 2010). The forthright Yu, who uses social media to buttress his campaign to prevent abuse of petitioners, was placed under a government gagging order after publicly contradicting propaganda suggesting that the rural petition system had achieved 'groundbreaking success' (Li 2010). Nowadays, however, $\mathrm{Yu}$ is regularly employed to lecture state officials on ethics and other moral guidelines in relation to the handling of protests and petitions, which exemplifies how the Centre manages to strengthen its rule both by keeping disruptive individuals firmly within its sphere of influence, as well as instilling its own agents with values less likely to instigate discontent in the first place.

\section{Conclusion}

Ultimately, then, the Centre uses various means of managing protests and petitions within China in an often Machiavellian manner to undergird and strengthen its own rule. It has been able to manipulate the decentralisation of state power and its resultant multilevel power structure to allow blame and responsibility for protests to be apportioned to lower level authorities, escaping accountability and maintaining its legitimacy as the 'benefactor' of the Chinese people. Moreover, even where violent repression is used in response to petitioning, the Centre is generally able to justify any such repression under Confucian mores, in turn strengthening its place at the top of the political hierarchy. Tolerance of and concessions to protests are more likely where dissenters utilise legal frameworks of contention provided for by the state, which inevitably presuppose and perpetuate the validity of the Centre's rule. Cooptation of particularly irksome protestors, or the reforms advocated by such protestors, also further reinforces the supremacy of the Centre's 'benevolent' rule.

Although protestors, like water in the stream, are indeed a strong force that might smooth the edges of a rock over time, inevitably that rock, like the Centre, can manipulate those waters and cement itself firmly within the stream for the foreseeable future. 


\section{Bibliography}

Baum, R 1992, 'Political Stability in Post-Deng China: Problems and Prospects', Asian Survey, 32(6), 491-505.

Cai, Y 2008a, 'Power Structure and Regime Resilience: Contentious Politics in China', British Journal of Political Science, 38, 411-32.

2008b, 'Social Conflicts and Modes of Action in China', The China Journal, 59, 89-109.

Chen, C 2009, 'Growing Social Unrest in China: Rising Social Discontents and Popular Protests', in G Wu \& H Lansdowne (eds), Socialist China, Capitalist China: Social Tension and Political Adaptation Under Economic Globalization, Routledge, New York.

Hintzen, G 1994, Protest Your Loyalty: An Analysis of the Right of Assembly, Procession, and Demonstration in the People's Republic of China, Research School CNWS, Leiden.

Li, L \& O'Brien, KJ 1996, 'Villagers and Popular Resistance in Contemporary China', Modern China, 22(1), 28-61.

Li, X 2010, 'The Ragged-Trousered Polemicist', Global Times, China, viewed 13 January 2011, <http://special.globaltimes.cn/2010-11/592690.html>.

Ling, LHM 1994, 'Rationalizations for State Violence in Chinese Politics: The Hegemony of Parental Governance', Journal of Peace Research, 31(4), 393-405.

McCormick, B 2009, 'Super Voice Girls and Freezing Point: Media, Hegemony, and Domination in the New China', in G Wu \& H Lansdowne (eds), Socialist China, Capitalist China: Social Tension and Political Adaptation Under Economic Globalization, Routledge, New York.

Mertha, A 2008, China's Water Warriors: Citizen Action and Policy Change, Cornell University Press, Ithaca.

O’Brien, KJ 2003, 'Neither Transgressive Nor Contained: Boundary-Spanning Contention in China', Mobilization: An International Journal, 8(1), 51-64.

O’Brien, KJ \& Li, L 1995, 'The Politics of Lodging Complaints in Rural China', The China Quarterly, 143, 756-83.

2004, 'Suing the Local State: Administrative Litigation in Rural China', The China Journal, 51, 75-96. 
- 2005, 'Popular Contention and its Impact in Rural China', Comparative Political Studies, 38(3), 235-59.

2006, Rightful Resistance in Rural China, Cambridge University Press.

Perry, EJ 2002, Challenging the Mandate of Heaven: Social Protest and State Power in China, ME Sharpe, New York.

- 2008, 'Chinese Conceptions of "Rights": From Mencius to Mao — and Now', Perspectives on Politics, 6(1), 37-50.

Weller, RP 2008, 'Responsive Authoritarianism', in B Gilley \& L Diamond (eds), Political Change in China: Comparisons with Taiwan, Lynne Rienner Publishers, London.

Wright, T 2010, Accepting Authoritarianism: State-Society Relations in China's Reform Era, Stanford University Press.

Wu, G 2009, 'Conclusion: Social Tension and Political Adaptation Under Globalization', in G Wu \& H Lansdowne (eds), Socialist China, Capitalist China: Social Tension and Political Adaptation Under Economic Globalization, Routledge, New York.

Zou, K 2009, 'Granting or Refusing the Right to Petition: The Dilemma of China's Xinfang System', in G Wu \& H Lansdowne (eds), Socialist China, Capitalist China: Social Tension and Political Adaptation Under Economic Globalization, Routledge, New York. 
This text taken from The ANU Undergraduate Research Journal Volume Five 2013, published 2014 by ANU Press, The Australian National University, Canberra, Australia. 